\title{
POLYESTER SAIL TECHNICAL WOVEN FABRIC BEHAVIOUR UNDER UNIAXIAL AND BIAXIAL TENSILE TESTS
}

\author{
Andrzej Ambroziak, Pawee KŁosowski \\ Gdansk University of Technology, Faculty of Civil and Environmental Engineering, Gdańsk, Poland \\ e-mail: ambrozan@pg.gda.pl; klosow@pg.gda.pl
}

\begin{abstract}
The paper is focused on the identification of mechanical properties of a sail technical woven fabric (yacht sailcloth polyester) style 480 AP with MTO (Medium Tempered Optimized) finish. The non-linear elastic behaviour of the fabric applied for sails is investigated under uniaxial and biaxial tensile tests. Comparison of non-linear elastic parameters with others polyester coated fabrics is made. This paper is intended to be an introduction to a comprehensive investigation on sail technical woven fabrics.
\end{abstract}

Keywords: sail fabric, polyester coated fabrics, textiles, mechanical properties, uniaxial tensile test, biaxial tensile tests

\section{Introduction}

The applications of composites materials are widespread in various branches of industry. Among others, coated woven fabrics (named architectural fabrics or technical woven fabrics) are widely applied. The coated woven fabrics are usually manufactured from polyester fibres, glass fibres or carbon fibres (generally, woven of two families of threads called the warp and weft) covered by a coating material (e.g.: PTFE, PVC) for greater strength and/or environmental resistance. In civil engineering, the technical woven fabrics are applied as membranes, pneumatic and hanging roofs (see e.g. Fig. 1). On the other hand, technical woven fabrics are used also for sailing ships (see Fig. 2). Analysis of sails as flexible membranes with two-dimensional theory started in the sixties of the XX century (see e.g. Nielsen, 1963). In the modern literature one find can papers regarding experimental studies (see e.g. Triki et al., 2011) and the numerical background (see e.g. Gasser et al., 2000; Badel et al., 2008). Only a few papers regarding the experimental analysis of sail cloths can be found, see e.g. Benfratello and Palizzolo (2010), Benfratello et al. (2013), where behaviour of the Dacron 360 woven fabric under uniaxial tensile tests with and without finish was investigated. On the other hand, Blicblau et al. (2008) investigated the forces applied resultant material deformations and stresses on a novel windsurfer sail. Spalatelu-Lazar et al. (2008) improved the quality and performances of sails by using an orthotropic membrane model, numerical experimentation and optimization methods. Le Maître et al. (1996) proposed an elastic string network model of sails. The equilibrium equation for this model was written in form of a minimization problem.

The parameters given by sailcloth manufactures in order to describe orthotropic and nonlinear behaviour of the sail fabric are insufficient for full description of its characteristics. An engineer who is supposed to perform the sail analysis should collect as well all information about the mechanical properties. From the naval engineer's point of view, a material to be used in sail manufacture should, first of all, have a smooth surface, have zero porosity ensuring effective air flow around the sail and be sea water resistant. On the other hand, the fabric of the sail must hold its shape over a wide wind range, and it must achieve long-term durability and ultra violet resistance. 


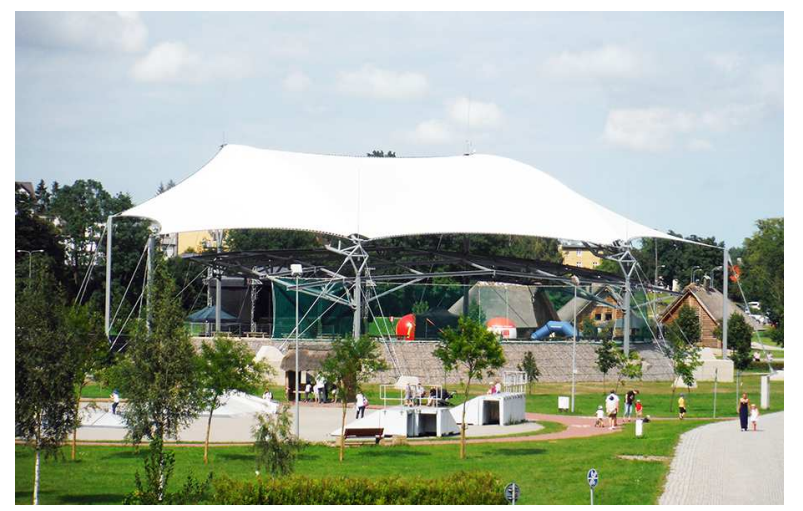

Fig. 1. Factoria amphitheatre in Pruszcz Gdański, Poland

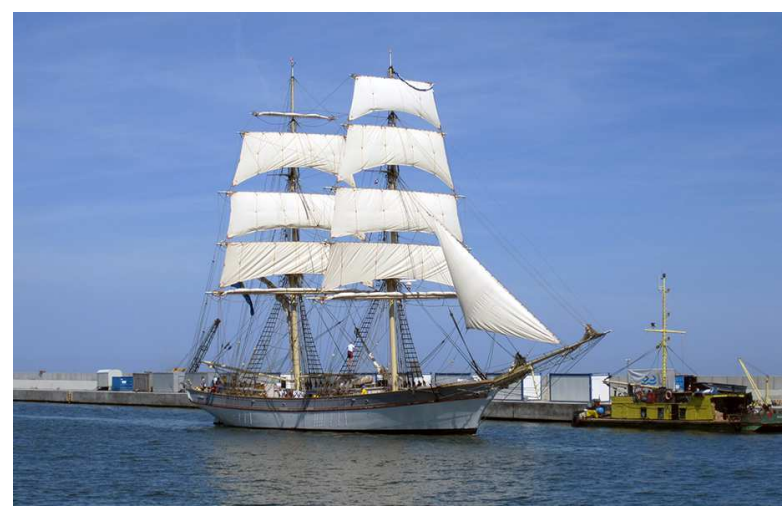

Fig. 2. Sailing vessels in Gdynia harbour, Poland

The aim of the present paper is to analyse, through experimental tests, the behaviour of the yacht sailcloth polyester style 480 AP with MTO finish under uniaxial and biaxial tensile tests and specify the non-linear elastic properties in form of sets of parameters.

\section{Material and methods}

The yacht sailcloth style 480 AP belongs to the polyester type of base fabric. The sailcloth weight is about $11.2 \mathrm{Sm}-\mathrm{oz}$. (11.2 sailmakers per square yards is equal to about $4.8 \mathrm{~N} / \mathrm{m}^{2}$ ). Material parameters necessary to design new shapes of sails and analyse their behaviour are not provided in technical specification. In order to perform the relevant assessment of the material, laboratory tests have been carried out.

A special set of constitutive equations must be applied for description of the fabric behaviour. The authors have good experience with the dense net model (see e.g. Ambroziak and Kłosowski, 2011), in which the behaviour of each family of threads is treated individually and is described by the individual longitudinal stiffness $F_{i}$. The threads stress increment of the warp $\Delta \sigma_{1}$ or weft direction $\Delta \sigma_{2}$ are calculated from the following equations

$$
\Delta \sigma_{1}=F_{1}\left(\varepsilon_{1}\right) \Delta \varepsilon_{1} \quad \Delta \sigma_{2}=F_{2}\left(\varepsilon_{2}\right) \Delta \varepsilon_{2}
$$

where $F_{1}\left(\varepsilon_{1}\right)$ and $F_{2}\left(\varepsilon_{2}\right)$ are material functions of the threads and are called the longitudinal stiffnesses. Several constitutive elastic, viscoplastic or viscoelastic approaches can be used to define these functions. They are usually specified on the basis of the uniaxial, or during more complex investigation, like e.g. biaxial laboratory tests. It should be noted that stress of a technical fabric 
is generally given in $[\mathrm{N} / \mathrm{m}]$ or $[\mathrm{kN} / \mathrm{m}]$, due to difficulties with thickness measurement, see e.g. Żyliński (1965). In such an approach, the results are thickness independent.

Basing on the geometrical relationship, the threads stress $\sigma_{i}$ and threads strain $\varepsilon_{i}$ can be expressed by the stress $\boldsymbol{\sigma}_{x}$ and strains $\varepsilon_{x}$ components in the plane stress state as follows

$$
\begin{aligned}
& \boldsymbol{\varepsilon}_{\xi}=\left\{\begin{array}{l}
\varepsilon_{1} \\
\varepsilon_{2}
\end{array}\right\}=\left[\begin{array}{ccc}
1 & 0 & 0 \\
\cos ^{2} \alpha & \sin ^{2} \alpha & \sin \alpha \cos \alpha
\end{array}\right]\left\{\begin{array}{c}
\varepsilon_{x 2} \\
\varepsilon_{x 2} \\
\gamma_{x 1 x 2}
\end{array}\right\}=\mathbf{T}_{x \xi} \boldsymbol{\varepsilon}_{x} \\
& \boldsymbol{\sigma}_{x}=\left\{\begin{array}{c}
\sigma_{x_{1}} \\
\sigma_{x_{2}} \\
\tau_{x_{1} x_{2}}
\end{array}\right\}=\left[\begin{array}{cc}
1 & \cos ^{2} \alpha \\
0 & \sin ^{2} \alpha \\
0 & \sin \alpha \cos \alpha
\end{array}\right]\left\{\begin{array}{l}
\sigma_{1} \\
\sigma_{2}
\end{array}\right\}=\left(\mathbf{T}_{x \xi}\right)^{\mathrm{T}} \boldsymbol{\sigma}_{\xi}
\end{aligned}
$$

where $\alpha$ is the inclination angle between the thread families during the deformation process. The angle between the thread families $\alpha$ changes during deformation is calculated in accordance with the current values of stress components $\sigma_{x 2}$ and $\tau_{x 1 x_{2}}$ in the fabric from the relation

$$
\alpha=\arctan \frac{\sigma_{x 2}}{\tau_{x 1 x 2}}
$$

Next, the relation between stress and strain in the plane stress state is written in the form

$$
\boldsymbol{\sigma}_{x}=\left(\mathbf{T}_{x \xi}\right)^{\mathrm{T}} \mathbf{F} \mathbf{T}_{x \xi} \boldsymbol{\varepsilon}_{x}=\mathbf{D}_{x} \boldsymbol{\varepsilon}_{x}
$$

where

$$
\mathbf{D}_{x}=\left[\begin{array}{ccc}
F_{1}\left(\varepsilon_{1}\right)+F_{2}\left(\varepsilon_{2}\right) \cos ^{4} \alpha & F_{2}\left(\varepsilon_{2}\right) \sin ^{2} \alpha \cos ^{2} \alpha & F_{2}\left(\varepsilon_{2}\right) \sin \alpha \cos ^{3} \alpha \\
F_{2}\left(\varepsilon_{2}\right) \sin ^{2} \alpha \cos ^{2} \alpha & F_{2}\left(\varepsilon_{2}\right) \sin ^{4} \alpha & F_{2}\left(\varepsilon_{2}\right) \sin ^{3} \alpha \cos \alpha \\
F_{2}\left(\varepsilon_{2}\right) \sin \alpha \cos ^{3} \alpha & F_{2}\left(\varepsilon_{2}\right) \sin ^{3} \alpha \cos \alpha & F_{2}\left(\varepsilon_{2}\right) \sin ^{2} \alpha \cos ^{2} \alpha
\end{array}\right]
$$

In uniaxial and biaxial tests, the stiffness values $F_{i}$ of the families can be determined. These values can be compared with the values obtained from both types of tests.

\section{Experimental tests}

The uniaxial and biaxial tensile tests with a constant displacement rate are chosen from a large group of experimental tests to model the material behaviour of a technical woven fabric. The uniaxial tensile experiments are the basic group of tests used for determination of mechanical properties of technical fabrics. One of the advantages of such tests is simplicity of preparation and cutting out of specimens which are generally cut along two orthogonal directions of the warp and weft threads. In basic uniaxial tensile tests, it is possible to specify stress and strains along investigated directions. In more sophisticated uniaxial tests, one can additionally specify Poisson's ratio. On the other hand, the biaxial tests are more complicated, and the application of specially designed stands is necessary. The test machines should apply tension in two directions with a different force ratio, constant in time. Good quality of the results depends on the type of an extensometer used to measure deformation in two directions simultaneously. Generally, the feature extraction method or digital image correlation based on artificial marks is used in a video extensometer for strain calculations (see e.g. Bathurst and Shinoda, 2004). In the feature extraction method, on the specimen surface, a non-destructive circles marks are made and then the distance between them is traced during the deformation process. When the specimen is deformed, its image changes accordingly. Following the changes of the marks coordinated on the specimen and the displacements, the strains can be calculated. In the biaxial tests, cross-shaped 
specimens are preferred. The biaxial tests reflects well an anisotropic character of technical fabrics.

Uniaxial tensile laboratory tests have been made using the computer-controlled Zwick 020 testing machine (Fig. 3). The experiments have been carried out according to the national standard PN-EN ISO 1421 (2001). Specimens from the same batch of fabric in three directions: along warp, along weft and with an angle of $45^{\circ}$ to both threads directions have been prepared. For each direction, five samples have been tested. Their dimensions were: width $50 \mathrm{~mm}$, length $900 \mathrm{~mm}$. The specimens have been subjected to tension with a displacement rate of grip equal to $100 \mathrm{~mm} / \mathrm{min}$ (constant grip displacement rate). The tests have been controlled by a video extensometer with the base about $50 \mathrm{~mm}$. The gauge length of each specimen (separation of curved grips) has been $100 \mathrm{~mm}$. All tests have been performed at room temperature (about $20^{\circ} \mathrm{C}$ ). All tests have been carried out up to specimen failure.

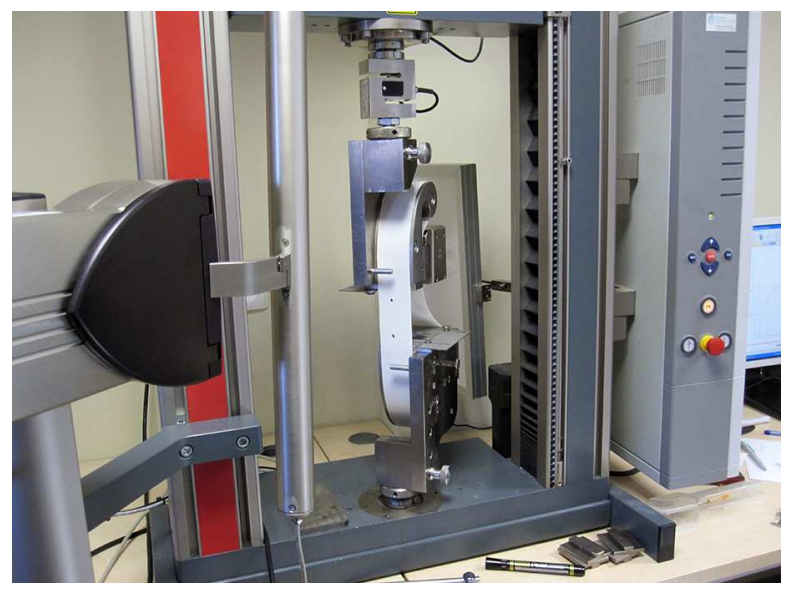

Fig. 3. Uniaxial laboratory test stand

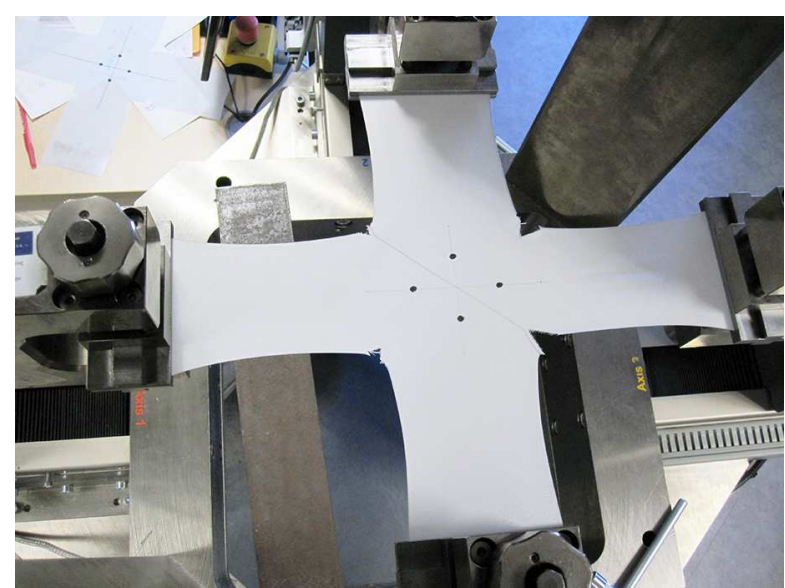

Fig. 4. Biaxial laboratory test stand

The biaxial tensile tests performed on the Zwick system BIAX 020 with a video extensometer attached (see Fig. 4), have been made for the cross-shaped specimens. There is no standard regulation on the method the tests should be performed. The arm width is $100 \mathrm{~mm}$, therefore, on the testing area of $100 \mathrm{~mm} \times 100 \mathrm{~mm}$ the gage length of about $50 \mathrm{~mm}$ in both directions has been chosen. In all tests, the initial grip separation of $300 \mathrm{~mm}$ has been used. The specimens have been subjected to tension (base constant force rate of $100 \mathrm{~N} / \mathrm{s}$ ) in the warp, weft and bias directions with load (stress) ratios 1:1, 1:2, 2:1 ( $\left.\sigma_{\text {warp }}: \sigma_{\text {weft }}\right)$. For each stress ratio, two samples up to failure have been tested. In the uniaxial and biaxial tensile tests, the measurements data (time, elongation and force) has been stored by every $0.01 \mathrm{~s}$ or force increment of $1 \mathrm{~N}$. 


\section{Results and discussion}

The stress-strain curves under uniaxial tensile tests are shown in Fig. 5. In general, mechanical properties in the weft and warp direction are different. The value of the Ultimate Tensile Strength (UTS) of specimens and the strain at rupture $\varepsilon_{R}$ are collected in Table 1. The UTS is the final stress sustained in a tensile test at the exact moment of rupture of fabric specimens. The results given in Table 1 are presented in the form $\bar{x} \pm \bar{s}_{x}$, where $\bar{x}$ is the mean value and $\bar{s}_{x}$ is the standard error of the mean value. The UTS values for the weft and warp are comparable, but the elongation and strain at break for the weft direction is about $50 \%$ higher than for the warp direction. The bias direction $\left(45^{\circ}\right)$ has the highest elongation and the smallest UTS value. In this case, the main threads (warp and weft) are angled for the load direction and are not going from one grip to the other.

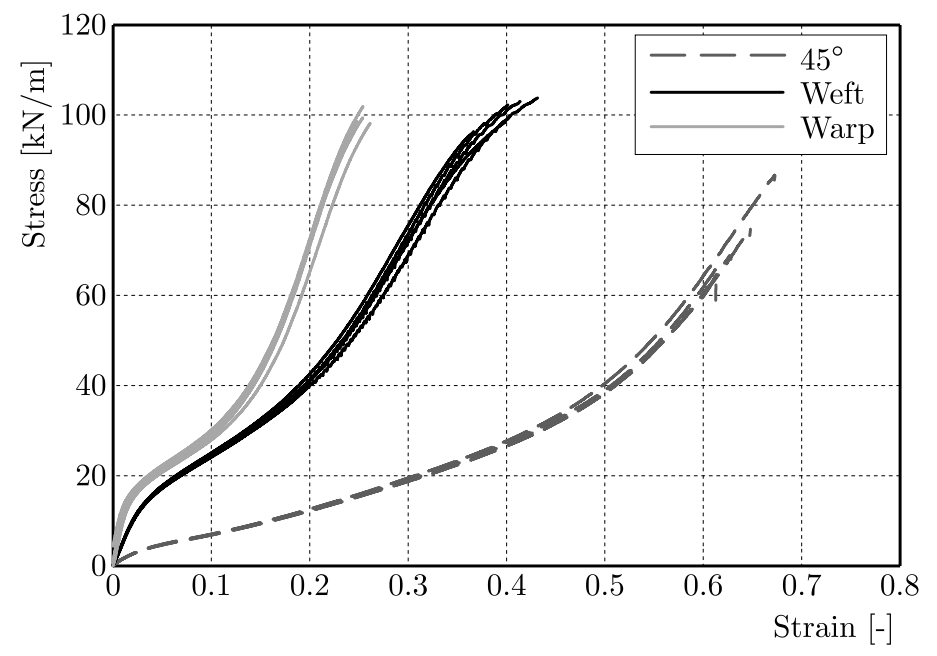

Fig. 5. Uniaxial test results

Table 1. Values of strain at break $\varepsilon_{R}$ and UTS

\begin{tabular}{|c|c|c|}
\hline & $\varepsilon_{R}[-]$ & UTS $[\mathrm{kN} / \mathrm{m}]$ \\
\hline \hline Weft & $0.40 \pm 0.01$ & $101 \pm 1$ \\
\hline Warp & $0.27 \pm 0.01$ & $99.2 \pm 0.9$ \\
\hline $45^{\circ}$ & $0.64 \pm 0.01$ & $74 \pm 5$ \\
\hline
\end{tabular}

Looking at the stress-strain curves (Fig. 5), the characteristic points of the curvature change can be specified. Then, for the strain range, a piecewise linear model (see e.g. Ambroziak, 2015a) can be used. In this concept, it is necessary to specify the longitudinal modules $F_{i}$ and the intersection points $P_{j}(j=1,2)$ for the specified strain values $\varepsilon_{P j}$ which define the range of applicability of a certain longitudinal modulus. The Marquardt-Levensberg algorithm (Marquardt, 1963) has been used to find the parameters that give the best fit between the constitutive equation and the experimental data. The parameters (and their standard deviation) for the piecewise linear model based on the uniaxial tensile test are given in Table 2. The parameters $F_{1}$ and $F_{3}$ are about $100 \%$ higher for the warp than for the weft direction. For the parameter $F_{2}$, the weft and the warp differences of $10 \%$ can be observed. These parameters can be easily applied in the dense net model (see e.g. Ambroziak and Kłosowski, 2011) to describe the coated woven fabric behaviour in FEM calculations of structures.

The results of the biaxial tensile tests for 1:1, 1:2, 2:1 load ratios are presented in Figs. 6 and 7 . It should be pointed that up to $10 \mathrm{kN} / \mathrm{m}$ stress range, the behaviour of the technical 
Table 2. Non-linear model parameters - uniaxial tests

\begin{tabular}{|c|c|c|c|}
\hline & Warp & Weft & $45^{\circ}$ \\
\hline \hline$F_{1}[\mathrm{kN} / \mathrm{m}]$ & $967 \pm 25$ & $491 \pm 4$ & $122 \pm 2$ \\
\hline$F_{2}[\mathrm{kN} / \mathrm{m}]$ & $159 \pm 2$ & $140 \pm 2$ & $60 \pm 1$ \\
\hline$F_{3}[\mathrm{kN} / \mathrm{m}]$ & $633 \pm 7$ & $344 \pm 4$ & $275 \pm 3$ \\
\hline$\varepsilon_{P 1}[-]$ & $0.0146 \pm 0.0009$ & $0.0297 \pm 0.0004$ & $0.004 \pm 0.001$ \\
\hline$\varepsilon_{P 2}[-]$ & $0.146 \pm 0.002$ & $0.203 \pm 0.003$ & $0.475 \pm 0.003$ \\
\hline
\end{tabular}

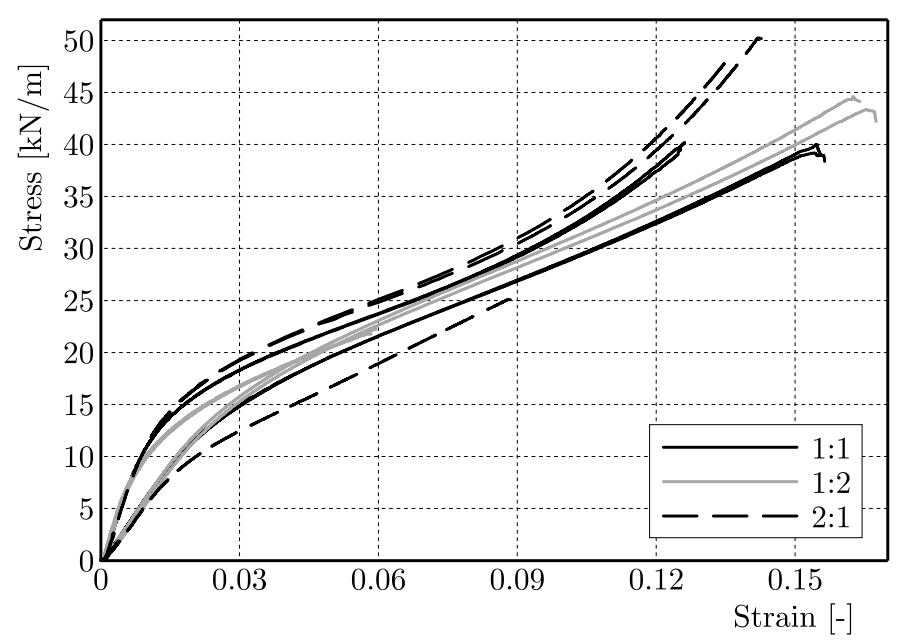

Fig. 6. Biaxial test results: 1:1, 1:2, 2:1

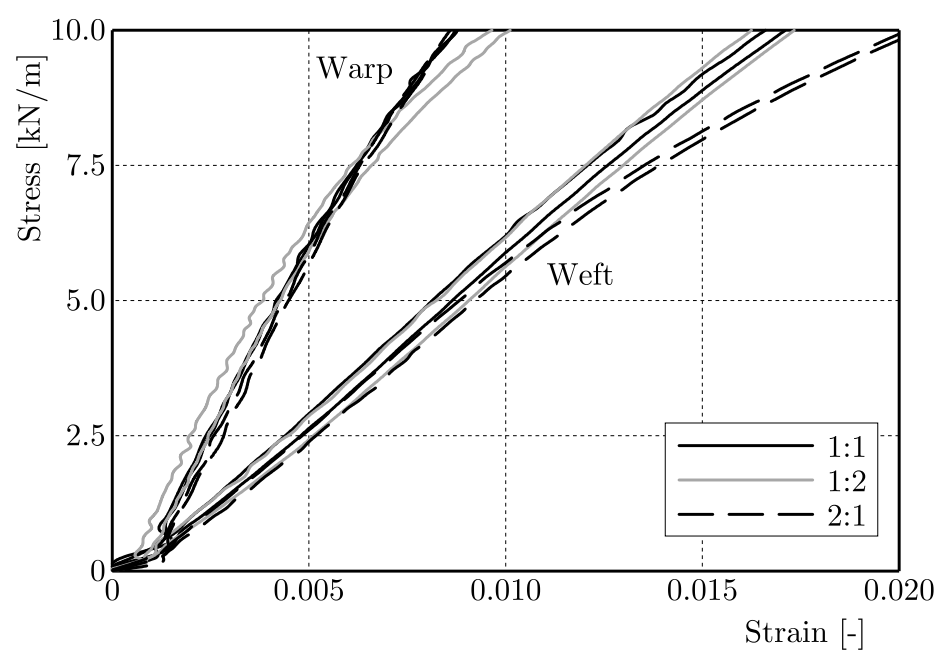

Fig. 7. Biaxial test results: 1:1, 1:2, 2:1 - stress range to $10 \mathrm{kN} / \mathrm{m}$

fabric under biaxial tensile tests is very similar. Biaxial bias direction tests results are given in Fig. 8. The load ratios $1: 2 \_45^{\circ}$ and $2: 1 \_45^{\circ}$ exhibit contraction for thread directions which have the smallest stress values. The highly loaded threads straighten while other ones become folded. For the 1:1_45 $5^{\circ}$ stress ratio, the strains are positive in both directions (expanded in both directions).

The stress and strain values at rupture of the specimens (see Figs. 9 and 10) are given in Table 3. The mean stress value at brake for $1: 1$ load ratio is about $40 \mathrm{kN} / \mathrm{m}$ and is about $40 \%$ of the mean uniaxial tensile strength (see Table 1). The bias direction for 1:1_45 load ratio reaches a stress value of $18.6 \mathrm{kN} / \mathrm{m}$. It is about $50 \%$ of the $1: 1$ biaxial stress and about $25 \%$ 


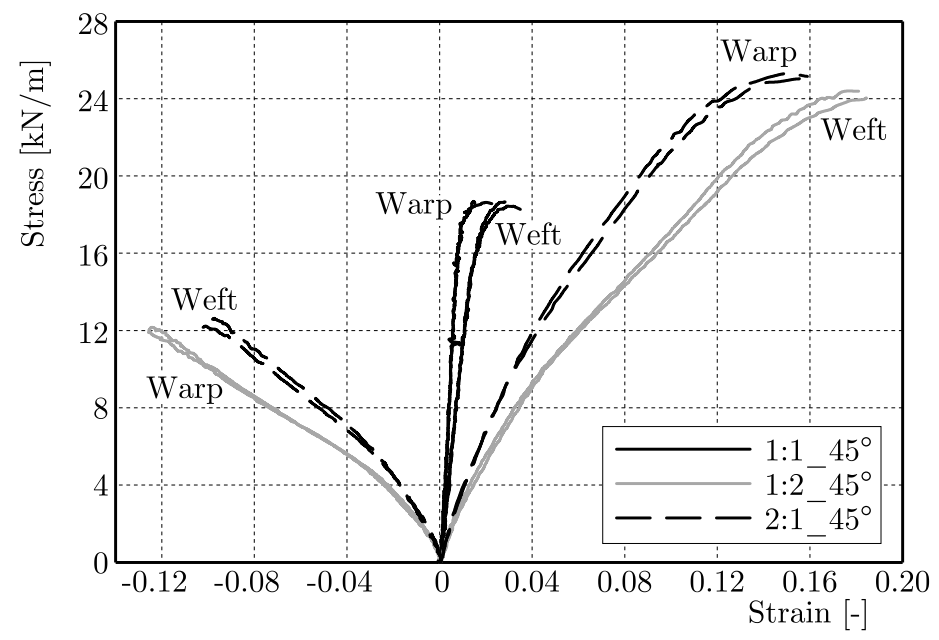

Fig. 8. Biaxial bias directions test results: 1:1_450, 1:2_450, 2:1_450
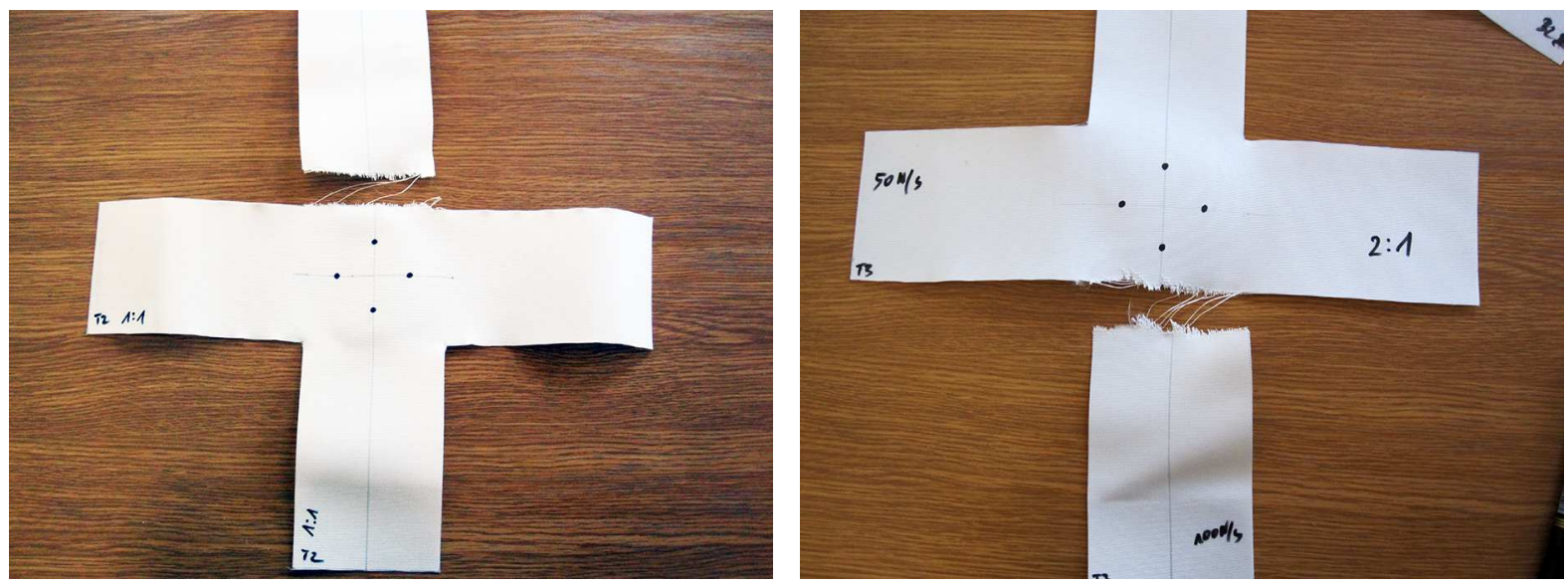

Fig. 9. Damaged specimens - biaxial test results
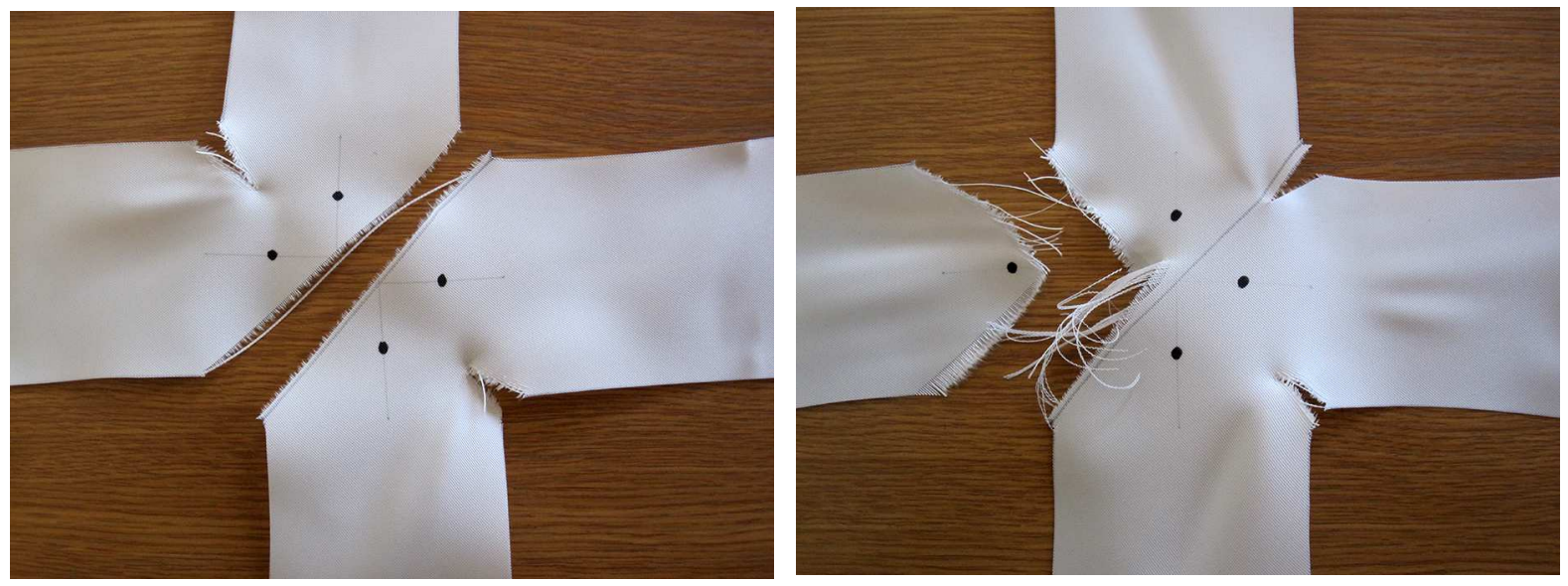

Fig. 10. Damaged $45^{\circ}$ specimens - biaxial test results

of the uniaxial bias tensile strength. It should be noted that when the load ratio is $1: 2$ and $2: 1$, the strength of the fabric increases by $10 \%-20 \%$ up to $44 \mathrm{kN} / \mathrm{m}$ and $49 \mathrm{kN} / \mathrm{m}$, respectively. This result can be explained by the failure mode of the specimen, see Figs. 9 and 10. For the 1:1, 1:2 and 2:1 load ratios, one of the cross arms is damaged. On the other hand, for the bias 
directions $1: 1 \_45^{\circ}, 1: 2 \_45^{\circ}, 2: 1 \_45^{\circ}$ tear of the cross specimen in the central region is observed. The parameters for the piecewise linear model based on the biaxial tensile test are given in Tables 4 and 5 . The value of $F_{1}$ parameter in the bias direction is about $100 \%$ higher than for the 1:1 load ratio in the warp and weft direction.

Table 3. Values of stress and strain at break

\begin{tabular}{|c|c|c|c|c|}
\hline Load ratios & $\sigma_{\text {warp }}[\mathrm{kN} / \mathrm{m}]$ & $\varepsilon_{\text {warp }}[-]$ & $\sigma_{\text {weft }}[\mathrm{kN} / \mathrm{m}]$ & $\varepsilon_{\text {weft }}[-]$ \\
\hline \hline $1: 1$ & $39.8 \pm 0.3$ & $0.1257 \pm 0.0005$ & $39.6 \pm 0.4$ & $0.1561 \pm 0.0006$ \\
\hline $1: 1 \_45^{\circ}$ & $18.6 \pm 0.1$ & $0.0198 \pm 0.003$ & $18.6 \pm 0.1$ & $0.0321 \pm 0.003$ \\
\hline $1: 2$ & $22.1 \pm 0.3$ & $0.0594 \pm 0.0003$ & $44.0 \pm 0.6$ & $0.167 \pm 0.002$ \\
\hline $1: 2 \_45^{\circ}$ & $12.1 \pm 0.1$ & $-0.1264 \pm 0.0001$ & $24.3 \pm 0.2$ & $0.185 \pm 0.001$ \\
\hline $2: 1$ & $49.3 \pm 1$ & $0.139 \pm 0.004$ & $24.6 \pm 0.5$ & $0.086 \pm 0.003$ \\
\hline $2: 1 \_45^{\circ}$ & $25.2 \pm 0.2$ & $0.1649 \pm 0.0001$ & $12.5 \pm 0.2$ & $-0.103 \pm 0.005$ \\
\hline
\end{tabular}

Table 4. Non-linear model parameters - warp

\begin{tabular}{|c|c|c|c|c|}
\hline & $1: 1$ & $1: 1 \_45^{\circ}$ & $1: 2$ & $2: 1$ \\
\hline \hline$F_{1}[\mathrm{kN} / \mathrm{m}]$ & $1140 \pm 2$ & $2240 \pm 130$ & $1429 \pm 23$ & $1228 \pm 6$ \\
\hline$F_{2}[\mathrm{kN} / \mathrm{m}]$ & $178 \pm 1$ & - & $193 \pm 1$ & $181 \pm 3$ \\
\hline$F_{3}[\mathrm{kN} / \mathrm{m}]$ & $326 \pm 6$ & - & - & $439 \pm 6$ \\
\hline$\varepsilon_{P 1}[-]$ & $0.0136 \pm 0.0001$ & - & $0.0094 \pm 0.0003$ & $0.0141 \pm 0.0001$ \\
\hline$\varepsilon_{P 2}[-]$ & $0.0975 \pm 0.0003$ & - & - & $0.102 \pm 0.002$ \\
\hline
\end{tabular}

Table 5. Non-linear model parameters - weft

\begin{tabular}{|c|c|c|c|c|}
\hline & $1: 1$ & $1: 1 \_45^{\circ}$ & $1: 2$ & $2: 1$ \\
\hline \hline$F_{1}[\mathrm{kN} / \mathrm{m}]$ & $595 \pm 2$ & $1110 \pm 13$ & $613 \pm 14$ & $606 \pm 7$ \\
\hline$F_{2}[\mathrm{kN} / \mathrm{m}]$ & $190 \pm 2$ & - & $199 \pm 5$ & $219 \pm 1$ \\
\hline$\varepsilon_{P 1}[-]$ & $0.0248 \pm 0.0002$ & - & $0.026 \pm 0.001$ & $0.0164 \pm 0.0005$ \\
\hline
\end{tabular}

Additionally, it can be shown in Fig. 11 that the biaxial tensile tests are comparable with the uniaxial tensile behaviour of the sailing technical fabric in a specific range of load. This characteristic is observed for a polyester type coated fabrics (see e.g. Ambroziak, 2015b). In Figs. 12 and 13 and Tables 6 and 7, uniaxial and biaxial test results for the chosen coated fabrics (AF 9032, FR 8540 and Precontraint 1202S) are compared with the tested 480 AP sail fabric. Detailed investigation on the FR 8540 and Precontraint 1202S coated fabrics are given by Ambroziak (2015a,b), respectively.

The shape and characteristic of the stress-strain curves from the warp and weft under uniaxial tensile tests (see Fig. 12) and 1:1 biaxial tensile tests (see Fig. 13) for the 480 AP fabric are similar to the Precontraint 1202S fabric. It can be concluded that bidirectional tension is applied during the manufacturing (coating) process of both these fabrics, because the shapes of stress-strain curves in the warp and weft directions are similar. For the AF 9032 and FR 8540 fabrics, the shape of stress-strain curves in the warp and weft direction are different. UTS values for the $480 \mathrm{AP}$, AF 9032 and Precontraint 1202S are comparable. The longitudinal stiffness $F_{1}$ in the warp direction for the $480 \mathrm{AP}$ is comparable with the other fabrics. On the other hand, it should be noted that total weights of the AF 9032 and Precontraint 1202S fabrics are two times bigger than the weight of the 480 AP fabric. It can be concluded that a different way of thread weaving of both fabrics has been applied. 


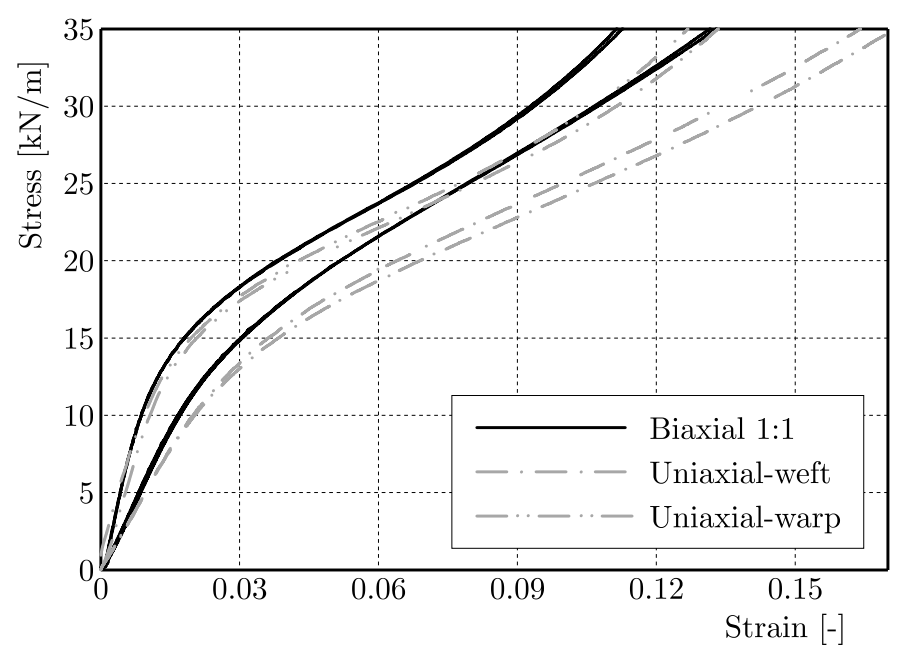

Fig. 11. Comparison of biaxial and uniaxial test results

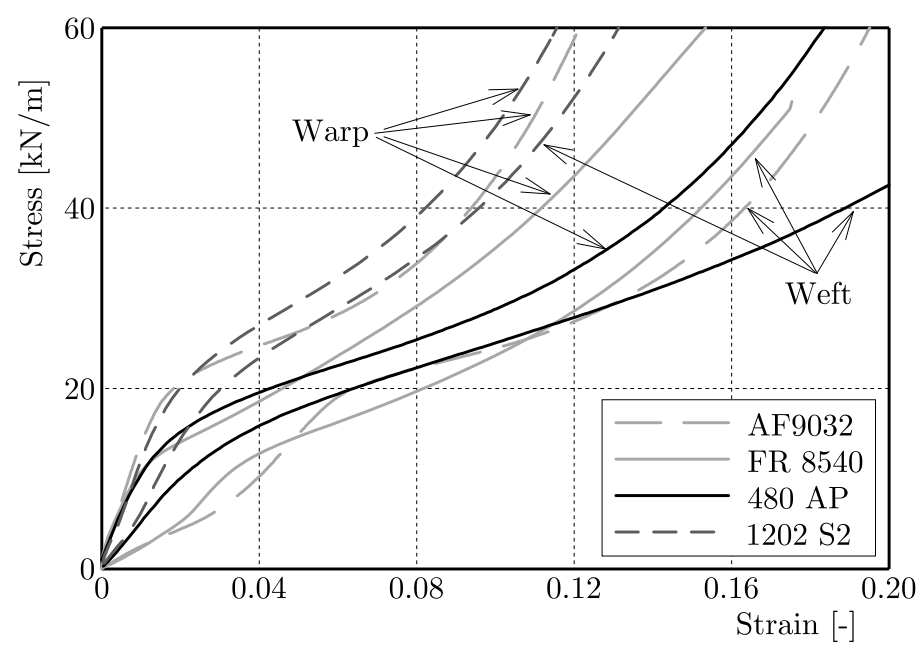

Fig. 12. Comparison of uniaxial test results for polyester fabrics

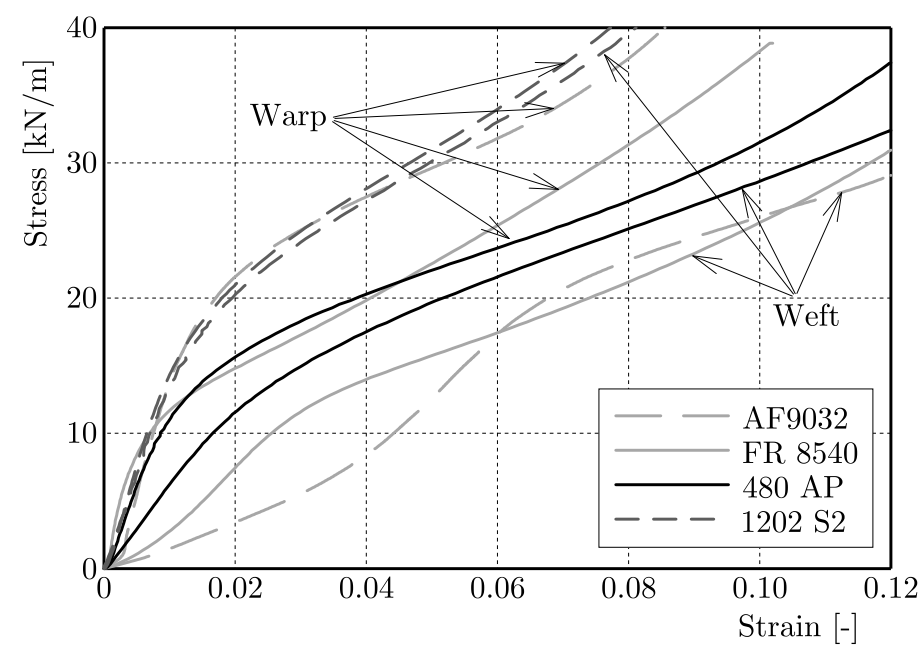

Fig. 13. Comparison of biaxial test results for polyester fabrics 
Table 6. Non-linear model parameters - uniaxial tests

\begin{tabular}{|c|c|c|c|c|}
\hline $\begin{array}{c}\text { Total weight } \\
{\left[\mathrm{g} / \mathrm{m}^{2}\right]}\end{array}$ & 480 & 1085 & 890 & 1050 \\
\hline \hline Weft & 480 AP & AF 9032 & FR 8540 & Precontraint 1202S \\
\hline \hline$F_{1}[\mathrm{kN} / \mathrm{m}]$ & $491 \pm 4$ & $193 \pm 5$ & $241 \pm 12$ & $650 \pm 26$ \\
\hline$F_{2}[\mathrm{kN} / \mathrm{m}]$ & $140 \pm 2$ & $465 \pm 15$ & $437 \pm 11$ & $288 \pm 3$ \\
\hline$F_{3}[\mathrm{kN} / \mathrm{m}]$ & $344 \pm 4$ & $105 \pm 2$ & $183 \pm 2$ & $841 \pm 8$ \\
\hline$F_{4}[\mathrm{kN} / \mathrm{m}]$ & - & $880 \pm 20$ & $444 \pm 5$ & - \\
\hline$\varepsilon_{P 1}[-]$ & $0.0297 \pm 0.0004$ & $0.034 \pm 0.002$ & $0.018 \pm 0.002$ & $0.030 \pm 0.001$ \\
\hline$\varepsilon_{P 2}[-]$ & $0.203 \pm 0.003$ & $0.064 \pm 0.004$ & $0.035 \pm 0.002$ & $0.1144 \pm 0.0007$ \\
\hline$\varepsilon_{P 3}[-]$ & - & $0.168 \pm 0.005$ & $0.124 \pm 0.004$ & - \\
\hline $\mathrm{UTS}[\mathrm{kN} / \mathrm{m}]$ & $101 \pm 1$ & $104 \pm 2$ & $67.5 \pm 0.5$ & $102 \pm 1$ \\
\hline \hline $\mathrm{Warp}$ & 480 AP & AF 9032 & FR 8540 & Precontraint $1202 \mathrm{~S}$ \\
\hline \hline$F_{1}[\mathrm{kN} / \mathrm{m}]$ & $967 \pm 25$ & $1280 \pm 15$ & $1070 \pm 5$ & $1170 \pm 20$ \\
\hline$F_{2}[\mathrm{kN} / \mathrm{m}]$ & $159 \pm 2$ & $197 \pm 1$ & $257 \pm 2$ & $300 \pm 4$ \\
\hline$F_{3}[\mathrm{kN} / \mathrm{m}]$ & $633 \pm 7$ & $1075 \pm 5$ & $482 \pm 4$ & $897 \pm 12$ \\
\hline$\varepsilon_{P 1}[-]$ & $0.0146 \pm 0.0009$ & $0.0142 \pm 0.0004$ & $0.0105 \pm 0.0002$ & $0.0164 \pm 0.0002$ \\
\hline$\varepsilon_{P 2}[-]$ & $0.146 \pm 0.002$ & $0.0981 \pm 0.0003$ & $0.100 \pm 0.001$ & $0.1002 \pm 0.0004$ \\
\hline $\mathrm{UTS}[\mathrm{kN} / \mathrm{m}]$ & $99.2 \pm 0.9$ & $116 \pm 2$ & $65 \pm 1$ & $108 \pm 1$ \\
\hline
\end{tabular}

Table 7. Non-linear model parameters - biaxial tests (1:1)

\begin{tabular}{|c|c|c|c|c|}
\hline Weft & 480 AP & AF 9032 & FR 8540 & Precontraint 1202S \\
\hline \hline$F_{1}[\mathrm{kN} / \mathrm{m}]$ & $595 \pm 2$ & $192 \pm 4$ & $241 \pm 12$ & $1300 \pm 10$ \\
\hline$F_{2}[\mathrm{kN} / \mathrm{m}]$ & $190 \pm 2$ & $462 \pm 12$ & $437 \pm 11$ & $300 \pm 5$ \\
\hline$F_{3}[\mathrm{kN} / \mathrm{m}]$ & - & $167 \pm 1$ & $183 \pm 2$ & $675 \pm 50$ \\
\hline$F_{4}[\mathrm{kN} / \mathrm{m}]$ & - & $875 \pm 12$ & $444 \pm 5$ & - \\
\hline$\varepsilon_{P 1}[-]$ & $0.0248 \pm 0.0002$ & $0.034 \pm 0.002$ & $0.018 \pm 0.002$ & $0.0145 \pm 0.0005$ \\
\hline$\varepsilon_{P 2}[-]$ & - & $0.064 \pm 0.004$ & $0.035 \pm 0.002$ & $0.095 \pm 0.001$ \\
\hline$\varepsilon_{P 3}[-]$ & - & $0.168 \pm 0.005$ & $0.124 \pm 0.004$ & - \\
\hline \hline Warp & 480 AP & AF 9032 & FR 8540 & Precontraint 1202S \\
\hline \hline$F_{1}[\mathrm{kN} / \mathrm{m}]$ & $1140 \pm 2$ & $1732 \pm 20$ & $1070 \pm 5$ & $1500 \pm 10$ \\
\hline$F_{2}[\mathrm{kN} / \mathrm{m}]$ & $178 \pm 1$ & $236 \pm 2$ & $257 \pm 2$ & $335 \pm 5$ \\
\hline$F_{3}[\mathrm{kN} / \mathrm{m}]$ & $326 \pm 6$ & $1045 \pm 3$ & $482 \pm 4$ & $750 \pm 25$ \\
\hline$\varepsilon_{P 1}[-]$ & $0.0136 \pm 0.0001$ & $0.0142 \pm 0.0004$ & $0.0105 \pm 0.0002$ & $0.012 \pm 0.001$ \\
\hline$\varepsilon_{P 2}[-]$ & $0.0975 \pm 0.0003$ & $0.0981 \pm 0.0003$ & $0.100 \pm 0.001$ & $0.095 \pm 0.001$ \\
\hline
\end{tabular}

\section{Conclusions}

The study presents test methods to investigate mechanical properties of a sail technical woven fabric. Additionally, several non-linear model parameters for polyester coated fabrics have been collected and compared. The identification of non-linear elastic properties has been successfully performed on the basis of uniaxial and biaxial tension tests for the dense net model. The material parameters, determined above, can be used in a direct way in FE analysis, where the problem of geometric nonlinearity is supplemented by physical nonlinearity of the fabric material. Based on the presented results, it can be concluded that it is possible to indicate the same types 
of technical woven fabrics for which the behaviour under biaxial stress state can be described by a uniaxial response (compare Fig. 11 and Fig. 7). One of the deciding factors is the type of textile weave (generally two orthogonal families of warp and weft threads). For engineering calculations in the preliminary design stage, one can apply the dense net model with uniaxial nonlinear parameters to describe biaxial behaviour of a technical woven fabric in the range 1:21:1-2:1 of load ratios. A modern laboratory equipment allows testing in different variants and computer storage of the results, important for a future identification process. Examples of such tests have been presented in the paper in order to understand the behaviour of the sail technical woven fabric better. The investigation confirms that the quality of the yacht sailcloth polyester is sufficiently high. The obtained results encourage the authors to continue the outlined research, also on the basis of extended experiments and to apply other types of constitutive models. This study may provide naval engineers and designers with a theoretical basis for a wide use of sail coated fabrics. Examples of presented laboratory tests and comparison of mechanical parameters make a step towards a better understanding of the behaviour of polyester coated fabrics.

\section{References}

1. Ambroziak A., 2015a, Mechanical properties of polyester coated fabric subjected to biaxial loading, Journal of Materials in Civil Engineering, 27, 11

2. Ambroziak A., 2015b, Mechanical properties of PVDF-coated fabric under tensile tests, Journal of Polymer Engineering, 35, 4, 377-390

3. Ambroziak A., KŁosowski P., 2011, Review of constitutive models for technical woven fabrics in finite element analysis, AATCC Review, 11, 3, 58-67

4. Bathurst R.J., Shinoda M., 2004, Strain measurement of geogrids using a video-extensometer technique, Geotechnical Testing Journal, 27, 5, 456-463

5. Badel P., Vidal-Salle E., Boisse P., 2008, Large deformation analysis of fibrous materials using rate constitutive equations, Computers and Structures, 86, 11-12, 1164-1175

6. Benfratello S., Cirello A., Palizzolo L., 2013, Effect of surface finish on the mechanical behaviour of Dacron 360 woven, Ocean Engineering, 70, 88-96

7. Benfratello S., Palizzolo L., 2010, Experimental characterization of Dacron 360 woven constitutive behaviour, Meccanica dei Materiali e delle Strutture, 1, 3, 13-23

8. Blicblau A.S., Singh M., McConnell E., Pleaner M., 2008, Stress analysis of a novice windsurfer sail by finite element analysis, Mathematical and Computer Modelling, 47, 11-12, $1108-1116$

9. Gasser A., Boisse P., Hanklar S., 2000, Mechanical behaviour of dry fabric reinforcements. 3D simulations versus biaxial tests, Computational Materials Science, 17, 1, 7-20

10. Le Maître O., Huberson S., Souza de Cursi J.E., 1996, Application of a non-convex model of fabric deformations to sail cut analysis, Journal of Wind Engineering and Industrial Aerodynamics, 63, $77-93$

11. Marquardt D.W., 1963, An algorithm for least squares estimation of parameters, Journal of the Society of Industrial and Applied Mathematics, 11, 431-441

12. Nielsen J.N., 1963, Theory of flexible aerodynamic surfaces, Journal of Applied Mechanics, 30, $435-442$

13. PN-EN ISO 1421:2001 Rubber- or plastics-coated fabrics - Determination of tensile strength and elongation at break 
14. Spalatelu-Lazar M., LÉné F., Turbé N., 2008, Modelling and optimization of sails, Computers and Structures, 86, 1486-1493

15. Triki E., Dolez P., Vu-Khanh T., 2011, Tear resistance of woven textiles - criterion and mechanisms, Composites Part B: Engineering, 42, 7, 1851-1859

16. Żyliński T., 1965, Textile Metrology (in Polish), Wydawnictwo Przemysłu Lekkiego i Spożywczego, Warsaw

Manuscript received December 16, 2016; accepted for print September 14, 2017 